\title{
Hydrocracking of Waste Cooking Oil into Biofuel Using Mesoporous Silica from Parangtritis Beach Sand Synthesis by Sonochemistry
}

Siti Salamah ( $\nabla$ sitisalamah@che.uad.ac.id)

Universitas Ahmad Dahlan https://orcid.org/0000-0003-2982-6968

\section{Wega Trisunaryanti}

Universitas Gadjah Mada Fakultas Matematika dan Ilmu Pengetahuan Alam

Indriana Kartini

Universitas Gadjah Mada Fakultas Matematika dan Ilmu Pengetahuan Alam

Suryo Purwono

Universitas Gadjah Mada Fakultas Teknik

\section{Research Article}

Keywords: Beach sand ,Dodecyl-amine ,Hydrocracking ,Mesoporous silica ,Sonochemistry

Posted Date: April 12th, 2021

DOI: https://doi.org/10.21203/rs.3.rs-276534/v1

License: (c) (i) This work is licensed under a Creative Commons Attribution 4.0 International License. Read Full License 


\section{Abstract}

High content of silica in beach sand can be synthesized into mesoporous silica (MS) using the sonochemistry method with dodecyl-amine (DDA) as a surfactant template. The preparation began by adding sodium silicate dropwise to DDA solution under the rotation speed of $120 \mathrm{rpm}$. The mixture was then added with $\mathrm{H} 2 \mathrm{SO} 4$ and sonicated at $37 \mathrm{Khz}$ at a temperature of $35^{\circ} \mathrm{C}$ for 20 minutes. The product was then filtered, washed, and dried at $50^{\circ} \mathrm{C}$ then calcined at $600{ }^{\circ} \mathrm{C}$ for $5 \mathrm{~h}$. After it was calcined, the sample was characterized by using FTIR, Surface Area Analyzer, XRD, SEM, and TEM as well as the acidity using pyridine vapor adsorption. The synthesized MS was then used as a catalyst in hydrocracking waste cooking oil in a semi-batch stainless steel reactor system at 450 \&C for $2 \mathrm{~h}$, under 20 $\mathrm{ml}$ min $-1 \mathrm{H} 2$ flow rate. The hydrocracking product of the liquid fraction was analyzed using GC-MS. The results showed that the best performance of the MS1 was produced by using the DDA concentration of $0.1 \mathrm{M}$, had optimum acidity at $\quad 1.7 \mathrm{mmolg}-1$, specific surface area of $233 \mathrm{~m} 2 \mathrm{~g} \mathrm{-1}$, total pore volume of $0.4 \mathrm{cc} / \mathrm{g}$, and average pore diameter of $7.70 \mathrm{~nm}$. The best MS1 catalyst produced liquid fraction with yield of $31.13 \mathrm{wt}$.\% which consisted of $11.10 \%$ diesel oil and $5.04 \%$ gasoline.

\section{Introduction}

Environmental pollution remains global concerns. Increasing usage of cooking oil leaves a huge amount of waste cooking oil (WCO). This waste has low economic value

and can contribute to increased environmental pollution. Therefore, coconut oil waste needs to be processed into other compounds that have higher economic value. One of the methods to process this waste is by cracking it into smaller molecules, hydrocarbon preferably, which can be used as biofuel. Waste cooking oil can be a reliable source of energy [1]. The hydrocarbon produced from this process has similar compounds to those found in petroleum fuel, in which it has higher energy density, lower viscosity, and higher stability [2]. Conversion of waste coconut oil into hydrocarbon requires an acidic catalyst that has a large surface area to accommodate the reaction. Among many types of catalyst available, mesoporous silica has drawn many attentions for the past years because of its high porosity properties and better performance [3]. Mesoporous materials are defined as material that has a pore size in the range of 2-50 $\mathrm{nm}$. The mesoporous structure could resolve and avoid diffusion limitation of bulky molecules during the catalytic process; hence, a better catalytic activity can be expected [3]. There are many synthesis routes to achieve mesoporous silica material, i.e. hydrothermal, sol-gel. Previous literature states that alkaline medium could affect the control of mesopore size distribution using sol-gel methods, hence, making it easier to control the material porosity [4].

Mesoporous silica materials can be synthesized using surfactants as metal oxide pore templates, followed by surfactant removal [5]. Compared to the sol-gel and the hydrothermal method, the sonochemical method has one obvious advantage in which it is relatively faster [6]. Zhao et al.[3] studied the effect of alkaline media on the process of controlling the wide distribution of mesoporous sizes in 
porous bimetallic silica using the sol-gel method. The result suggests that the formation of mesoporous using the sol-gel method depends on the balance between $\mathrm{SiO}_{4}$ and CTAB.

Mahardika et al.[7] investigated the transesterification of waste cooking oil using CaO/MCM-41 catalyst synthesized from Lapindo mud by the sonochemical method. The results showed that the MCM-41 material synthesized by the sonochemical method has a regular hexagonal structure and a uniform pore shape with a specific surface area and large pore volume and pore diameter. The pore volume obtained from the sonochemical synthesis of MCM- 41 catalyst was $0.37-0.68 \mathrm{~cm}^{3} / \mathrm{g}$ with a pore diameter of 2.5$3.5 \mathrm{~nm}$. The superior properties of silica synthesized from the sonochemical method implies the immense potential that this method has. To increase the porosity properties and its performance, a good templating agent is strictly needed. Dodecyl amine is well known for its use in the synthesis of highly ordered mesoporous silica [8].

As one of the silica-containing materials, beach sand has silica composition, depending on its geographical location. Beach sands are one of the examples of carbonate sand which have a silicon dioxide content of 72-84 \% [9]. Higher silica content could increase the economic value of beach sand if converted into a more valuable product. Silica and silicon dioxide could be used for any purposes, i.e. adsorbent, desiccant, filter media, and catalysator component. Silica-based material shows excellent promises in the adsorbent and catalyst industry if treated or converted into mesoporous material [10].

This research studied the usage of mesoporous silica in hydrocracking waste cooking oil. The silica used was extracted from the beach sand of Parangtritis Beach. The extracted silica was then used to synthesize silica and mesoporous silica. In mesoporous silica synthesis, dodecyl amine (DDA) was used as a template to create mesoporosity by using the sonochemistry method. The advantage of using the sonochemistry method in synthesizing the catalyst is that it does not require high temperature. Moreover, it takes a relatively short time to produce the desired catalyst [11]. The effect of template concentration was studied by analyzing the materials characteristics and its mesoporous silica activity with hydrocracking waste cooking oil.

\section{Experimental}

\subsection{Materials and Methods for Sample Preparation}

The materials used in this study were Silica synthesis from Parangtritis beach sand; Dodecyl amine supplied by Fisher Scientific, distilled water, $\mathrm{HCl}$ supplied by Mallinckrodt, $\mathrm{NaOH}$ supplied by VWR Chemicals, $\mathrm{AgNO}_{3}, \mathrm{C}_{5} \mathrm{H}_{5} \mathrm{~N}$ and silica standard supplied by Sigma Aldrich.

Silica was extracted from Parangtritis beach sand which contains $\mathrm{SiO}_{2}$ using the Reflux method [9]. Mesoporous silica was synthesized from previously extracted silica using the sonochemistry method with DDA surfactant as a template [10]. Powder $\mathrm{SiO}_{2}$ was dissolved in a solution of $1.5 \mathrm{M} \mathrm{NaOH}$ and stirred at a temperature of $40^{\circ} \mathrm{C}$ for 30 minutes to obtain soluble sodium silicate. As much as $0.5 \mathrm{~g} \mathrm{DDA}$ 
was dissolved in a $25 \mathrm{~mL}$ solvent mixture of distilled water and ethanol with a ratio of 1:1, at a temperature of $40{ }^{\circ} \mathrm{C}$ for 30 minutes. Sodium silicate was added dropwise to DDA solution under rotation speed of $120 \mathrm{rpm}$ at room temperature.

The mixture was left for one hour before it was added with $6 \mathrm{M} \mathrm{H}_{2} \mathrm{SO}_{4}$ to get a pH value of 5 . The reaction mixture was stirred in Sonoficator at $37 \mathrm{kHz}$ and $35^{\circ} \mathrm{C}$ for 20 minutes. The solution was left under a static condition at room temperature for 1 hour. The product was then filtered and washed with distilled water until filtration reached the $\mathrm{pH}$ value of 6 . Finally, it was dried at $50{ }^{\circ} \mathrm{C}$ for 4 hours. The dried product was then calcined at $600{ }^{\circ} \mathrm{C}$ for 5 hours with a heating rate of $5{ }^{\circ} \mathrm{C} / \mathrm{min}$ to remove the surfactant template.

\subsection{General procedure:}

The functional group in silica, as well as the presence and disappearance of the DDA template from silica was observed and analyzed using Fourier-Transform Infrared Spectrometer (FTIR) using KBr disc technique. The acidity of sand, silica, and mesoporous silica were analyzed using gravimetric base adsorption. In this research, pyridine was used as base probe molecules. The acidity was calculated with the following formula,

\section{Acidity $=\frac{\mathrm{WCSH} H \mathrm{~N}}{\mathrm{~W}_{\mathrm{Y}} \times \mathrm{M}_{C 5 H 5 \mathrm{~N}}} \times 1000 \frac{\mathrm{mmol}}{\mathrm{g}}$}

where $\mathrm{W}_{\mathrm{C} 5 \mathrm{H} 5 \mathrm{~N}}$ is the weight of adsorbed pyridine vapor $(\mathrm{g}), \mathrm{W}_{\mathrm{Y}}$ is the weight of mesopore silica and $\mathrm{M}_{\mathrm{C} 5 \mathrm{H} 5 \mathrm{~N}}$ is the molecular weight of pyridine $(79.01 \mathrm{~g} / \mathrm{mol})$. Pore size and volume were analyzed using $\mathrm{N}_{2}$ gas sorption analysis which was carried out using Quanthachrome NOVAtouch. Adsorptiondesorption isotherms were measured by the multipoint method. The total surface areas were calculated by the BET method. BJH desorption model was used to provide pore size distribution. The mesoporous silica crystallinity was analyzed using X-ray diffraction (XRD) analysis and the analysis was performed using Rigaku Miniflex 600 with Cu Ka monochromatized radiation source $\left(\lambda=1.54^{\circ} \mathrm{A}\right)$, operated at $30 \mathrm{kV}$, $10 \mathrm{~mA}$, scan speed $10^{\circ} \mathrm{min}^{-1}$, and scan range $2-80^{\circ}$. Morphology of mesoporous silica was characterized with Scanning Electron Microscope (SEM) and Transmission Electron Microscope (TEM) to analyze its pores structure.

Hydrocracking waste cooking oil was done by putting 0.2 grams of mesoporous silica into the catalyst container and 10 grams of waste cooking oil into the oil container. Waste cooking oil sample and mesoporous silica were put into a hydrocracking reactor. The reactor was set at a temperature of $450{ }^{\circ} \mathrm{C}$ per 2 hours with a flow of hydrogen gas of $20 \mathrm{ml} / \mathrm{min}$. The catalytic activity of mesoporous silica was evaluated in hydrocracking waste cooking oil by a reactor. The liquid produced by Hydrocracking waste cooking oil was analyzed by Gas Chromatography-Mass Spectrometer(GC-MS, Shimadzu QP2010S). 


\section{Results}

\subsection{Silica}

The silica was extracted from the beach sand analyzed using SEM-EDX. The extracted silica has the following characteristics. It has $21.19 \%$ of $\mathrm{Si}, 34.22 \%$ of $\mathrm{O}, 43.17 \%$ of $\mathrm{C}, 1 \%$ of $\mathrm{Br}$ and $0.42 \%$ of $\mathrm{Na}$. It has a surface area of $54.43 \mathrm{~m}^{2} / \mathrm{g}$, a pore volume of $0.006 \mathrm{cc} / \mathrm{g}$, and a pore diameter average of $3.13 \mathrm{~nm}$ (12). Commercial silica which was analyzed with SEM-EDX in contrast has a $40.91 \%$ composition of Si and $59.09 \%$ of 0 . It also has a characteristics surface area of $162.36 \mathrm{~m}^{2} / \mathrm{g}$, a pore volume of $0.68 \mathrm{cc} / \mathrm{g}$, and a pore diameter of $16.81 \mathrm{~nm}$. Silica extracted from beach sand has a smaller surface area as it still contains impurities such as carbon, $\mathrm{Br}$, Sodium ( $\mathrm{Na}$ ). $\mathrm{Na}$ comes from a solution of $\mathrm{NaOH}$ or $\mathrm{NaCl}$ contained in seawater salt.

\subsection{Mesoporous Silica}

The synthesized mesoporous silica (MS) was divided into three samples: MS1, MS2, and MS3. The first sample, MS1, used DDA concentration of $0.1 \mathrm{M}$. MS2 and MS3 used DDA concentration of $0.2 \mathrm{M}$ and 0.3 $M$ respectively. After the samples were processed using the sonochemistry method, MS1 was immediately filtered and washed whilst MS2 and MS3 were left for 1 hour before filtered and washed until the samples free from $\mathrm{Cl}^{-}$or the $\mathrm{pH}$ value is neutral. The samples were calcinated at $600{ }^{\circ} \mathrm{C}$ to remove its template and then characterized by FTIR before and after calcination, as shown in Figure 1. The broadband at a wavenumber of $470 \mathrm{~cm}^{-1}$ showed bending vibration, indicating the presence of Si-O$\mathrm{Si}$. There was an influentially strong intensity band at $1118.7 \mathrm{~cm}^{-1}$ which represented Si-OH stretching; this is due to the interaction of the $\mathrm{O}-\mathrm{H}$ group originating from the water found on the silica surface through hydrogen bonds. It was generally known that $450-1300 \mathrm{~cm}^{-1}$ range was the unique silica band [14]. The broadband at a wavenumber of $1620 \mathrm{~cm}^{-1}$ showed bending $\mathrm{Si}-\mathrm{OH}$ as there were new bands at $1635 \mathrm{~cm}^{-1}$ and a strong band at $3448.7 \mathrm{~cm}^{-1}$ after the calcination, which represented water $\mathrm{O}-\mathrm{H}$ bending and O-H stretching, respectively. The broadband at a wavenumber of $1465.9 \mathrm{~cm}^{-1}$ showed primer amine. Spectra at wavenumber of $3425 \mathrm{~cm}^{-1}$ showed stretching vibrations of $\mathrm{N}-\mathrm{H}$ primary amines. These bands indicate that the DDA template was still present in the MS. After the calcination process, the DDA template was expected to be removed. The DDA removal from MS was proven by the disappearance of $1465.96 \mathrm{~cm}^{-1}$ and $2924 \mathrm{~cm}^{-1}$ peaks.

\subsection{Acidity Test}

MS surface acidity was determined using the gravimetric acidity test with pyridine as a base probe molecule. The results are $0.2 \mathrm{mmol} / \mathrm{g}$ for sand, $0.96 \mathrm{mmol} / \mathrm{g}$ for silica and $1.7 \mathrm{mmol} / \mathrm{g}$ for MS1, MS2 2.64 and MS3 $1.60 \mathrm{mmol} / \mathrm{g}$. The higher acidity of MS showed its potential to be used as a catalyst that 
requires acid sites, such as hydrocracking. The greater the DDA concentration, the lower the acidity. This is due to the uneven distribution of the pores on the layer surface of the material [14].

\subsection{Gas Sorption Analysis}

The synthesized silica and mesoporous silica were analyzed using Gas Sorption Analyzer (GSA) to determine their porosity character. The isotherm graph and specific surface area were calculated using the BET equation. Pore volume, average pore diameter, and pore size distribution were calculated using $\mathrm{BJH}$. The results of characterization by GSA determine the classification of mesoporous materials based on their pore size according to the material classification [15]. The results of the characterization of GSA are in table 1.

\section{Table 1}

The porosity property of silica and MS obtained from Parangtritis beach sand

\begin{tabular}{|llll|}
\hline Samples & $\begin{array}{l}\text { Specific Surface Area } \\
\left(\mathbf{m}^{2} / \mathbf{g}\right)\end{array}$ & Total pore volume $(\mathrm{cc} / \mathrm{g})$ & $\begin{array}{l}\text { Average Pore Diameter } \\
(\mathrm{nm})\end{array}$ \\
\hline Silica $(\mathrm{S})$ & 54.43 & 0.006 & 3.13 \\
\hline MS1 & 233 & 0.4 & 7.70 \\
\hline MS2 & 114 & 0.2 & 9.20 \\
\hline MS3 & 231 & 0.3 & 6.20 \\
\hline
\end{tabular}

All samples were in mesoporous range, 2-50 nm synthesized hexagonal mesoporous silica with a pore diameter of $2.1 \mathrm{~nm}$ [16]. Although silica without template was in mesoporous material range, its pore volume was shallow, compared to MS1, MS2 and MS3, indicating that low porosity formation occurred in that material. It was observed that the amount of template affects the porosity formation in MS synthesis. The more templates used, the higher the porosity properties, i.e., specific surface area, pore volume. This phenomenon was in agreement with previous research [13]. Isotherm graph on both MS1, MS2, and MS3 was shown in Figure 2. All samples were confirmed to have a mesoporous structure, based on the presence of their hysteresis loop. These isotherm patterns are similar to the IUPAC type IV isotherm model, with the hysteresis loop similar to type H4. The hysteresis loop of type H4 was well known for materials that have narrow slit-like pores, particles with internal voids of irregular shape and broad size distribution [16], [17].

Figure 3 visualizes the mesoporous silica which has a reasonably wide pore size distribution. It is ranging from 1-10 nm, following the pore size range of the mesoporous which is 2-50 nm meaning that MS is mesoporous as expected. Besides that, there is also the distribution of pores in the micropore region. This 
indicates that the MS obtained is micropore and mesopore-sized, which is referred to as hierarchical mesoporous [18] [19].

\subsection{Mesoporous Silica Crystallinity}

MS crystallinity was examined using XRD, Figure 4. Excluding MS2, it was found that MS has an amorphous silica phase, where it was in agreement with previous studies [6],[17],[20],[21]. The diffractogram of MS2 showed an anomaly compared to the other series around $2 \theta$ and $15^{\circ}$, where broadpeak could be seen. This phenomenon could be caused by the crystal formed in undecomposed surfactant found beneath the sample.

\subsection{Characterization silica, MS with SEM and TEM}

Characterization of MS with SEM-EDX and TEM was done to reveal the morphology of the synthesized mesoporous silica structure. SEM image was necessary to characterize the 3D surface morphology of mesoporous silica.

SEM is needed to determine the surface of the synthesized mesoporous silica. From figure 5 , the mesoporous structure with the formation of small grains, the morphological structure is close to the MS structure synthesized

It was seen from Figure 5. that extracted silica has a sizeable irregular chunk of silica.

The higher of DDA template concentration, there appears to be a blockage on the surface MS, this is probably due to the lack of evenness of the silicate in the template which is caused by the inappropriate sonochemistry frequency. On the other hand, it has much spherical silica that seems to be connected by an intercrystallite joint.

TEM images of MS were shown in Figure 6. The white dots on the TEM images represent the porosity that is present in the MS. The pore distribution data, Figure 3, could help to confirm that the white dot at the MS was a small mesopore that was detected by GSA. From SEM and TEM imaging, it could be concluded that dodecyl amine could act as a template, forming small particles that later could form a bigger aggregate through the intercrystallite joint, which has a small mesopore. This phenomenon was in agreement with previous literature [16].

TEM image is needed to ensure that the synthesized MS has pore gaps according to the results of the GSA analysis. The TEM image in Figure 6 appears to have clear pores like wormholes. The use of DDA as a non-ionic template made the pore structure of MS irregular. Pores with a wormhole-like structure were obtained $[19,23]$. At MS2, pore-blocking occurred and it caused the pore surface area to decrease, according to the results of the GSA analysis in table 4. Likewise, the higher the DDA concentration in MS3, the less regular the pore structure could get. 


\subsection{Catalytic Activity}

The best synthesized mesoporous silica catalyst, MS1, was used for hydrocracking catalyst used in cooking oil. MS1 has a specifically higher surface area than silica and MS2 and MS3. Activity MS1 has a liquid fraction of $31.13 \%$. The surface area was higher and the location of the acid site could be responsible for this phenomenon, where the acid site of mesoporous silica could reside deep beneath the catalyst. While the feed and product could come in and out easily, the chance of the feed finding the active site before they exit the catalyst become slimmer. This hypothesis seems to be responsible for the relatively high amount of oxygenated product [22].

\section{Table 2}

The free Fatty acid composition of waste cooking

\begin{tabular}{|lll|}
\hline Free Fatty Acid & Lipid Numbers & Composition \% \\
\hline Myristic acid & C14:0 & 7.36 \\
\hline Palm itic acid & C16:0 & 33.46 \\
\hline Petroselinic acid & C18:1 & 50.25 \\
\hline Stearic acid & C18:0 & 3.08 \\
\hline Oleic acid & C18:1 & 2.6 \\
\hline Linoleic acid & C18:2 & 2.81 \\
\hline
\end{tabular}

\section{Table 3}

The product distribution of hydrocracking waste cooking oil across the catalyst 


\begin{tabular}{|llll|}
\hline Product Distribution & \multicolumn{3}{l}{ Catalyst } \\
\cline { 2 - 4 } & Sand & Silica & Mesoporous Silica \\
\hline Liquid (wt\%) & 19.41 & 17.98 & 31.13 \\
\hline Gas (wt\%) & 22.97 & 46.94 & 17.64 \\
\hline Coke (wt\%) & 0.88 & 1.13 & 3.86 \\
\hline Residue (wt\%) & 56.74 & 33.95 & 47.36 \\
\hline Alkane/Alkene & 0.85 & 1.27 & 1.01 \\
\hline Gasoline $\left(\mathrm{C}_{5}-\mathrm{C}_{12}, w t \%\right)$ & 12.39 & 11.53 & 5.04 \\
\hline Diesel oil $\left(\mathrm{C}_{13}-\mathrm{C}_{18}, \mathrm{wt} \%\right)$ & 5.28 & 4.11 & 11.10 \\
\hline Oxygenated product $(\mathrm{wt} \%)$ & 1.74 & 2.34 & 15.00 \\
\hline
\end{tabular}

Under hydrocracking reaction, waste cooking oil was converted into liquid, gas, and coke, where the data could be seen in Table 3. Mesoporous silica showed superior performance in terms of producing liquid fraction but was still able to avoid over-cracking mechanism, indicated by a relatively low gas fraction produced. Over-cracking phenomenon marked by the increase of gas fraction, which is not considered to be the main product. MS1 had a better ability to produce more liquid fraction than the other catalyst. Its ability to avoid over-cracking could be owed to the good pore structure of the catalyst, where mesoporous on the surface of the catalyst enables the feed to enter the catalyst as well as releasing the product with ease. As a consequence of having higher porosity properties, mesoporous silica has a larger chance to accumulate more coke, that silica.

The ratio of alkane/alkene from the product of each catalyst reflected the ability of the catalyst to transport hydrogen atom into the intermediate molecules. Although MS1 has significantly higher acidity, determined by pyridine gas adsorption, compared to silica and sand, its alkane/alkene ratio was lower than silica. The location of the acid site could be responsible for this phenomenon, where the acid site of mesoporous silica could reside deep beneath the catalyst. While the feed and product could come in and out easily, the chance of the feed finding the active site before they exit the catalyst become slimmer. This hypothesis seems to be responsible for the relatively high amount of oxygenated product.

As the feed could come and go easily because of the mesopore structure, which is hypothesized to be responsible for low alkane/alkene ratio, the reaction frequency of this kind of system would be very low, leading to the high percentage of oxygenated product in the liquid fraction. The two phenomena, low alkane/alkene ratio and high oxygenated product, seems to be related to each other, where the two of them are the results of low reaction frequency, It means that many reactions take place.

Even though the mesoporous structure seems to bring disadvantage in the hydrocracking process of waste cooking oil, the mesoporous structure was responsible for the selectivity of diesel oil fraction, as 
presented in Fig 7. The product distribution of waste cooking oil catalyzed by MS1 turned into bimodal, where the compound with the highest yields is $\mathrm{C}_{11}$ and $\mathrm{C}_{17}$. It seems that the presence of mesoporous structure in silica shifted the catalyst selectivity and also allowed the formation of diesel oil fraction by cutting less carbon chain. This task could only be done due to its mesoporous structure with dispersed acid sites. The main mechanism that turned fatty acid into hydrocarbon and its shorter hydrocarbon chain are decarboxylations, decarbonylation, and hydrodeoxygenation [23]. The reaction mechanism of hydrocracking waste cooking oil [24] can be seen in figure 8 .

The Hydrodeoxygenation mechanism could be easily seen by the presence of $\mathrm{C}_{18}$ hydrocarbon, where there is no carbon loss during the process [23]. It can be noticed that waste cooking oil does not contain any $\mathrm{C}_{17}$ fatty acid, but the liquid product contains $\mathrm{C}_{17}$ hydrocarbon in quite a large quantity. This phenomenon implies that either decarbonylation or decarboxylation occurred to $\mathrm{C}_{18}$ fatty acid. This series of phenomena implies that the synthesized mesoporous silica has strong desorptive nature, making the product could exit the catalyst with more ease, which favors the formation of diesel oil fraction.

\section{Conclusions}

The mesoporous silica was successfully synthesized from Parangtritis Beach sand using the sonochemical method. High porosity properties of MS have optimal acidity at $1.7 \mathrm{mmol} / \mathrm{g}$. The specific surface area of $233 \mathrm{~m}^{2 /} \mathrm{g}$, pore volume $0.4 \mathrm{cc} / \mathrm{g}$, average pore diameter in mesoporous range $7.70 \mathrm{~nm}$. The presence of mesoporous silica was observed with SEM and TEM imaging. The mesopore structure of MS allows the formation and selectivity towards diesel oil fraction $\left(\mathrm{C}_{13}-\mathrm{C}_{18}\right), 11.10 \%$, but this formation inevitably produces a high oxygenated product, $15.00 \%$.

\section{Declarations}

\section{Acknowledgements}

The authors would like to thank the General Directorate of Higher Education, Ministry of Education and Culture of Indonesia for the financial support given under the scheme of Universitas Gadjah Mada Doctoral Dissertation Research (PDD) grant with contract number 208/UN. 1/DITLIT/DIT-LIT/PT/2020.

\section{Availability of data and material}

Data and materials are all available and prepared, authors will be pleased to provide them if requested during the publication process.

\section{Author contribution:}

First Author: Collect data and analyze the draft manuscript 
Correspondent Author: write manuscript and proofreading

Co-Author: as a data analysis consultant

\section{Funding Statement :}

This scientific publication is funded by the General Directorate of Higher Education, Ministry of Education and Culture, Indonesia.

\section{Compliance with ethical standards:}

The research conducted used sand beach and coconut oil as samples with no animal nor human sample at all, hence did not require compliance with ethical standard.

\section{Conflict of interest:}

All authors declare no conflicts of interest in this paper.

\section{Consent to participate}

All the authors have made a significant contribution to this manuscript, have seen and approved the final manuscript.

\section{Consent for Publication}

All authors have agreed to submit this manuscript to Silicon.

\section{References}

1. C. Panadare and V. K. Rathod, "Applications of Waste Cooking Oil Other Than Biodiesel: A Review," vol. 12, no. 3, pp. 55-76, (2015).

2. Trisunaryanti, S. Larasati, T. Triyono, N. R. Santoso, and C. Paramesti, "Selective production of green hydrocarbons from the hydrotreatment of waste coconut oil over Ni- And NiMo-supported on aminefunctionalized mesoporous silica," Bull. Chem. React. Eng. Catal., vol. 15, no. 2, pp. 415-431, (2020), doi: 10.9767/bcrec.15.2.7136.415-431.

3. Zhao, G. Wang, L. Qin, H. Li, Y. Chen, and B. Liu, "Synthesis and catalytic cracking performance of mesoporous zeolite y," Catal. Commun., vol. 73, pp. 98-102, (2016), doi:

10.1016/j.catcom.2015.10.020. 
4. Zhou, J. Sun, B. Ren, F. Wang, X. Wu, and S. Bai, "Effects of alkaline media on the controlled large mesopore size distribution of bimodal porous silicas via sol-gel methods," Powder Technol., vol. 259, pp. 46-51, (2014), doi: 10.1016/j.powtec.2014.03.060.

5. Barrabino, "Synthesis of mesoporous silica particles with control of both pore diameter and particle size," Thesis, pp. 1-63, (2011).

6. Yang et al., "Hydrothermal synthesis of plugged micro/mesoporous Al-SBA-15 from spent fluid catalytic cracking catalyst," Mater. Chem. Phys., vol. 222, no. October 2018, pp. 227-229, (2019), doi: 10.1016/j.matchemphys.2018.10.026.

7. B. P. Mahardika, W. Trisunaryanti, T. Triyono, D. P. Wijaya, and K. Dewi, "Transesterification of used cooking oil using $\mathrm{CaO} / \mathrm{MCM}-41$ catalyst synthesized from lapindo mud by sonochemical method," Indones. J. Chem., vol. 17, no. 3, pp. 509-515, (2017), doi: 10.22146/ijc.26561.

8. V.,Jadhav, \& Vavia, P. R. (2017). Dodecylamine template-based hexagonal mesoporous silica (HMS) as a carrier for improved oral delivery of fenofibrate. AAPS PharmSciTech, 18(7), 2764-2773. doi: 10.1208/s12249-017-0761-x

9. Irzon, "Komposisi Kimia Pasir Pantai di Selatan Kulon Progo dan Implikasi terhadap Provenance Geochemical Character of Coastal Sediments from Southern Kulon Progo with Implications for Provenance," vol. 19, no. 1, pp. 31-46, (2018).

10. Y. Lin and Y. W. Chen, “Preparation of spherical hexagonal mesoporous silica," J. Porous Mater., vol. 12, no. 2, pp. 95-105, (2005), doi: 10.1007/s10934-005-6766-y.

11. S. Xia, Y. H. Hou, G. Chang, W. Z. Weng, G. Bin Han, and H. L. Wan, "Partial oxidation of methane into syngas ( $\mathrm{H} 2+\mathrm{CO})$ over effective high-dispersed Ni/SiO 2 catalysts synthesized by a sol-gel method," Int. J. Hydrogen Energy, vol. 37, no. 10, pp. 8343-8353, (2012), doi: 10.1016/j.jhydene.2012.02.141.

12. Salamah,S.,Trisunaryanti,W., Kartini, Purwono, S. (2021), "Synthesis and characterization of mesoporous silica from beach sand as silica source", Proseding The $4^{\text {th }}$ International conference On Chemical \& Material Engineering, IOP.Conf.Series: Material Science and Engineering doi:10.1088/1757-899X/1053/1/012027.

13. Lin et al., "Direct synthesis without addition of acid of Al-SBA-15 with controllable porosity and high hydrothermal stability," Microporous Mesoporous Mater., vol. 142, no. 2-3, pp. 526-534, (2011), doi: 10.1016/j.micromeso.2010.12.043.

14. G. Kadam et al., "Hexagonal Mesoporous Silica-Supported Copper Oxide (CuO/HMS) Catalyst: Synthesis of Primary Amides from Aldehydes in Aqueous Medium," Chempluschem, vol. 82, no. 3, pp. 467-473, (2017), doi: 10.1002/cplu.201600611.

15. R. Pauly, Y. Liu, T. J. Pinnavaia, S. J. L. Billinge, and T. P. Rieker, "Textural mesoporosity and the catalytic activity of mesoporous molecular sieves with wormhole framework structures," J. Am. Chem. Soc., vol. 121, no. 38, pp. 8835-8842, (1999), doi: 10.1021/ja991400t.

16. Nuntang, S. Yousatit, T. Yokoi, and C. Ngamcharussrivichai, "Tunable mesoporosity and hydrophobicity of natural rubber/hexagonal mesoporous silica nanocomposites," Microporous 
Mesoporous Mater., vol. 275, no. June 2018, pp. 235-243, (2019), doi:

10.1016/j.micromeso.2018.09.004.

17. L. Ramasamy, S. Khan, E. Repo, and M. Sillanpää, "Synthesis of mesoporous and microporous amine and non-amine functionalized silica gels for the application of rare earth elements (REE) recovery from the waste water-understanding the role of $\mathrm{pH}$, temperature, calcination and mechanism in Light REE and Hea," Chem. Eng. J., vol. 322, pp. 56-65, (2017), doi: 10.1016/j.cej.2017.03.152.

18. J. Sotomayor, K. A. Cychosz, and M. Thommes, "Characterization of Micro/Mesoporous Materials by Physisorption: Concepts and Case Studies," Acc. Mater. Surf. Res, vol. 3, no. 2, pp. 34-50, (2018).

19. Coasne, "Multiscale adsorption and transport in hierarchical porous materials," New J. Chem., vol. 40, no. 5, pp. 4078-4094, (2016), doi: 10.1039/c5nj03194j.

20. Cheng, J. Cai, and Y. Ke, "Synthesis of Large-Pore Silica Microspheres Using Dodecylamine as a Catalyst, Template and Porogen Agent," J. Inorg. Organomet. Polym. Mater., vol. 29, no. 4, pp. 14171421, (2019), doi: 10.1007/s10904-019-01086-3.

21. Wijaya, K., Saputri, W.,D., Aziz I.,T.,A., Wangsa, Heraldy E.,Hakim L., Suseno A., Utami M.,2021, "Mesoporous silica preparation Using Sodium Bicarbonate as template and Application of the silica for Hydrocarcking of used cooking oil into Biofuel", J Silicon, doi: 1007/s12633-021-00946-3

22. Hartati, H., Trisunaryanti, W., Mukti, R. R., Kartika, I. A., Firda, P. B. D., Sumbogo, S. D., Prasetyoko, D., \& Bahruji, H. (2020). Highly selective hierarchical ZSM-5 from kaolin for catalytic cracking of Calophyllum inophyllum oil to biofuel. Energy Inst.. Vol. 93, no.6, pp. 2238-2246 doi: 10.1016/j.joei.2020.06.006

23. Trisunaryanti, S. Larasati, S. Bahri, Y.L., Ni'mah,L.Efianti,K.Amri, R. Nuryono, and S.D.sumbogo, "Performance comparison of Ni-Fe loaded on Nh2-fungtionalized mesoporous silica and beach sand in the hydrotreatment of waste palm cooking oil," Journal of Enviromental Chemical Engineering, vol.8, no 6, p.1004477,2020. doi: 10.1016/j.jece.2020.104477

24. Yıldız, A., Goldfarb, J.L. \& Ceylan, S., 2019, Sustainable hydrocarbon fuels via "one-pot" catalytic deoxygenation of waste cooking oil using inexpensive, unsupported metal oxide catalysts, Fuel, 263, August 2019, 116750. doi: 10.1016/j.fuel.2019.116750.

\section{Figures}




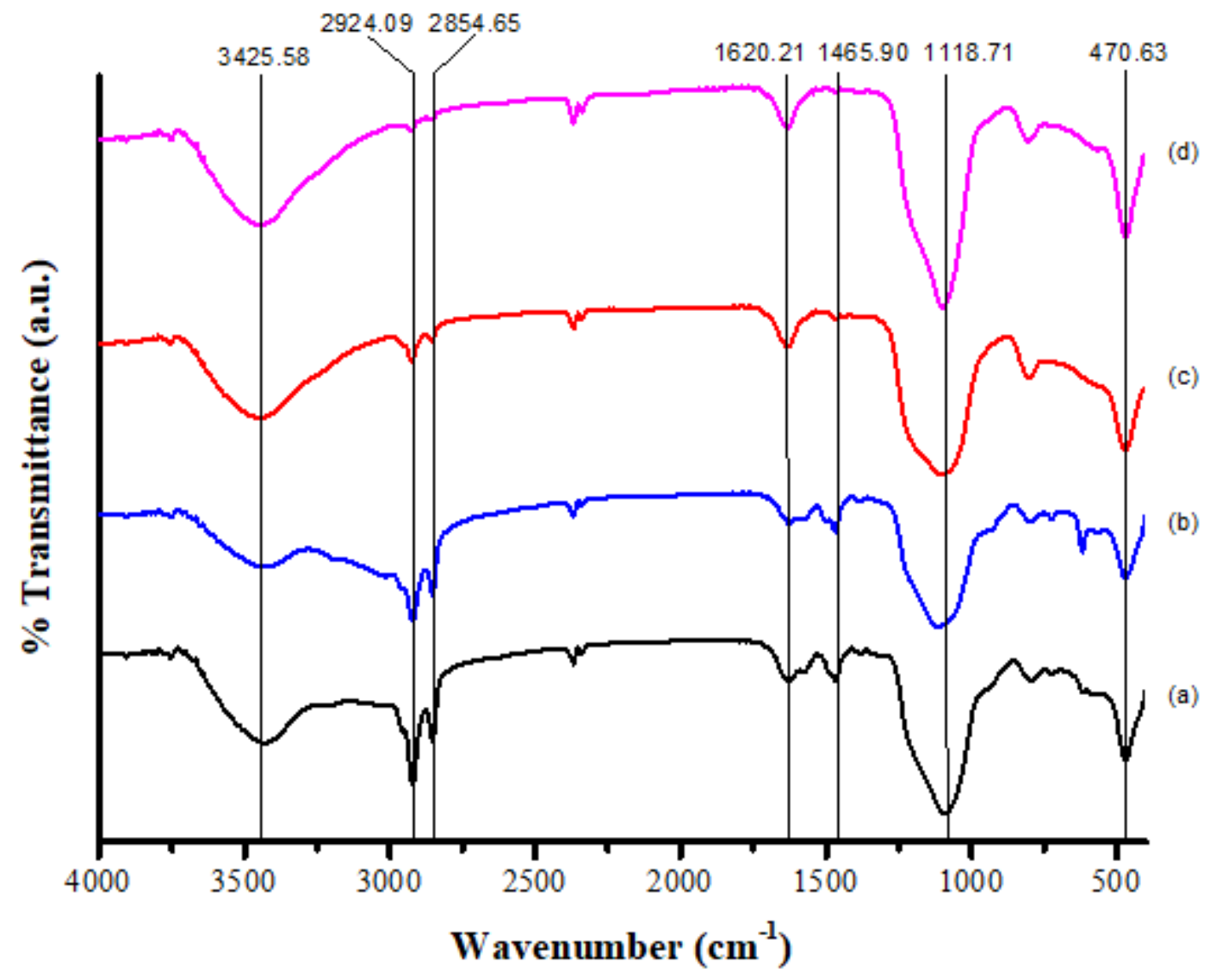

Figure 1

Infra-Red spectra of (a) MS2 (b) MS3 before calcination, (c) MS2 (d) MS3 after calcination 


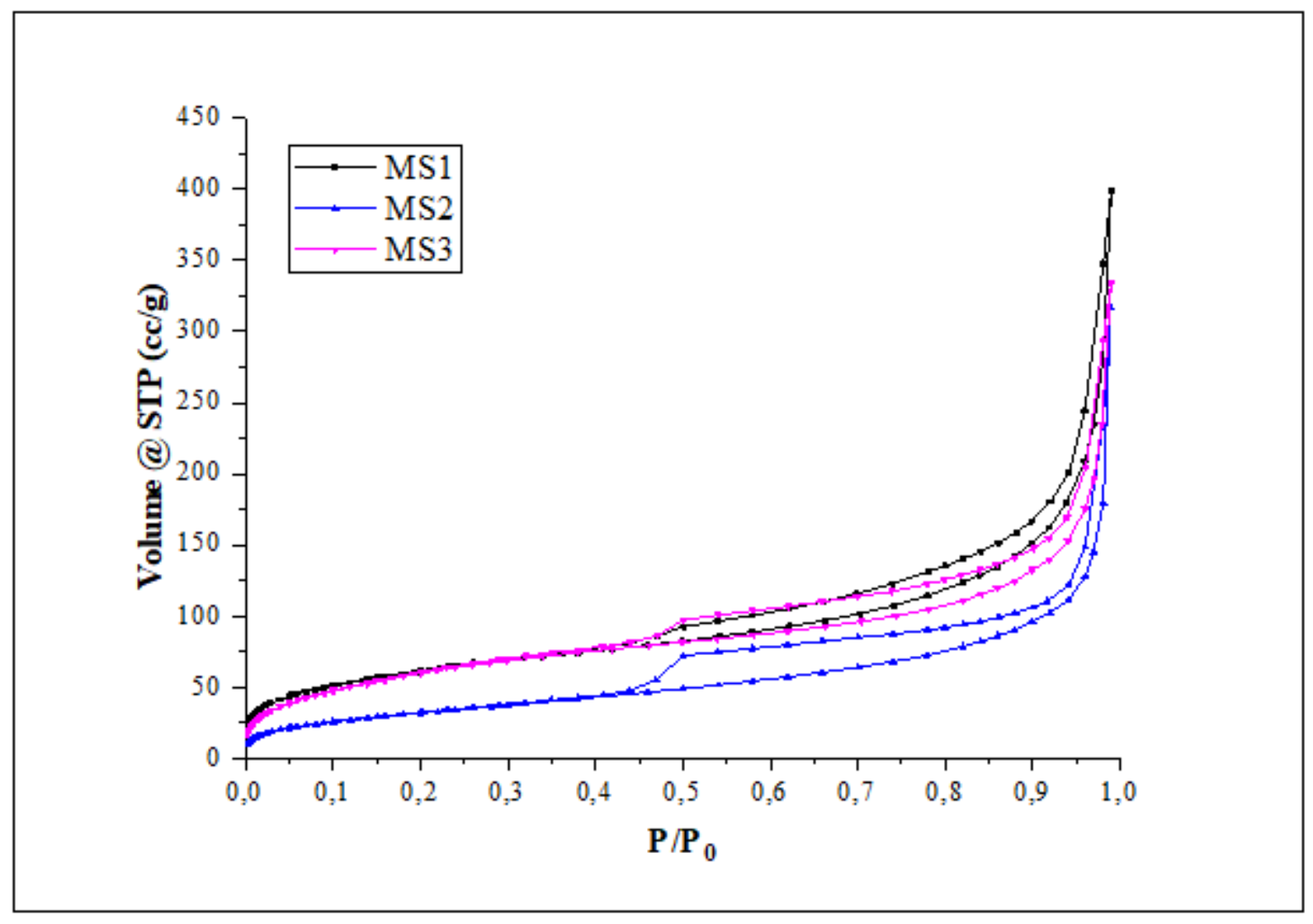

Figure 2

Adsorption-desorption isotherm of N2 graph 


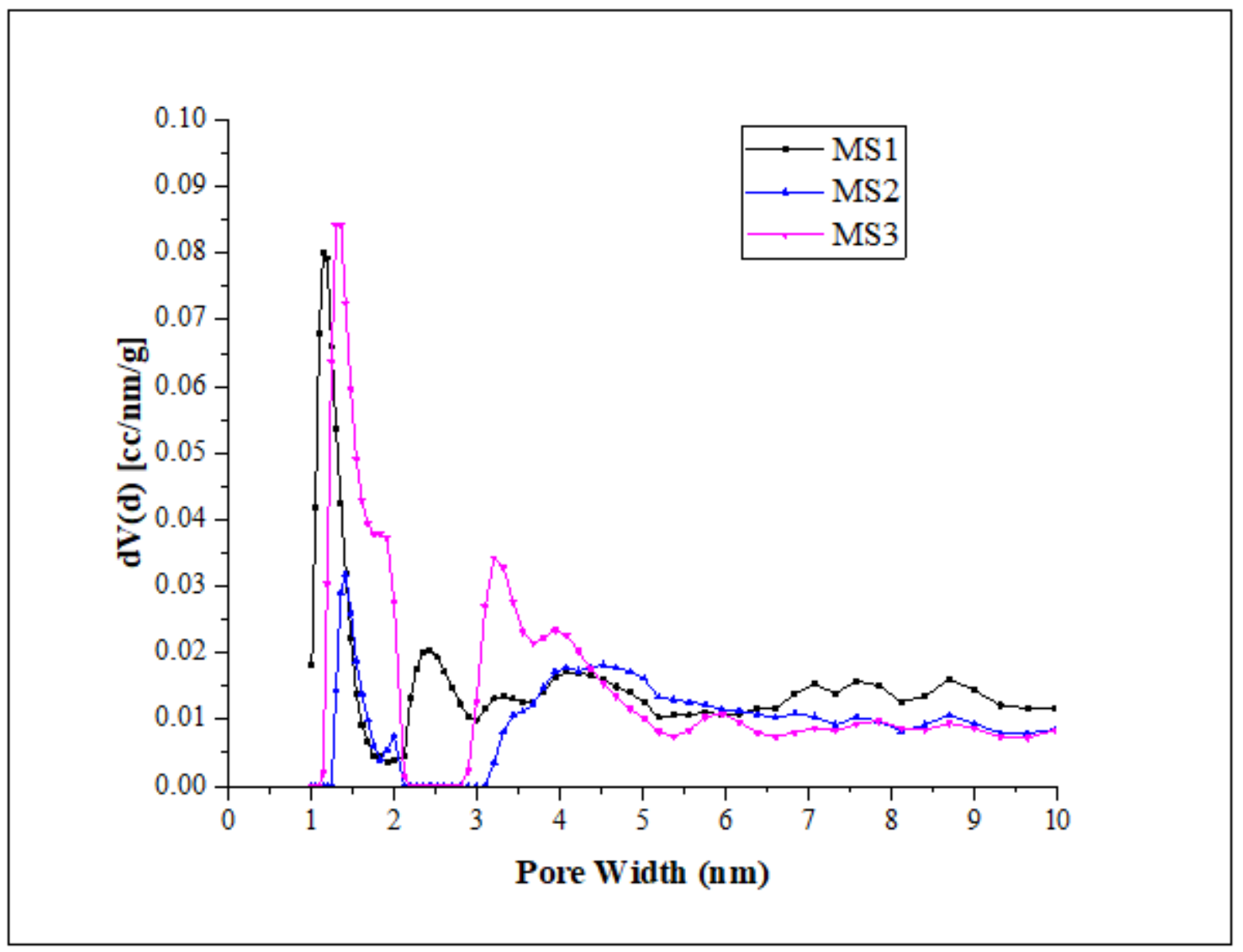

Figure 3

Pore size distribution graph of MS1, MS2 and MS3 


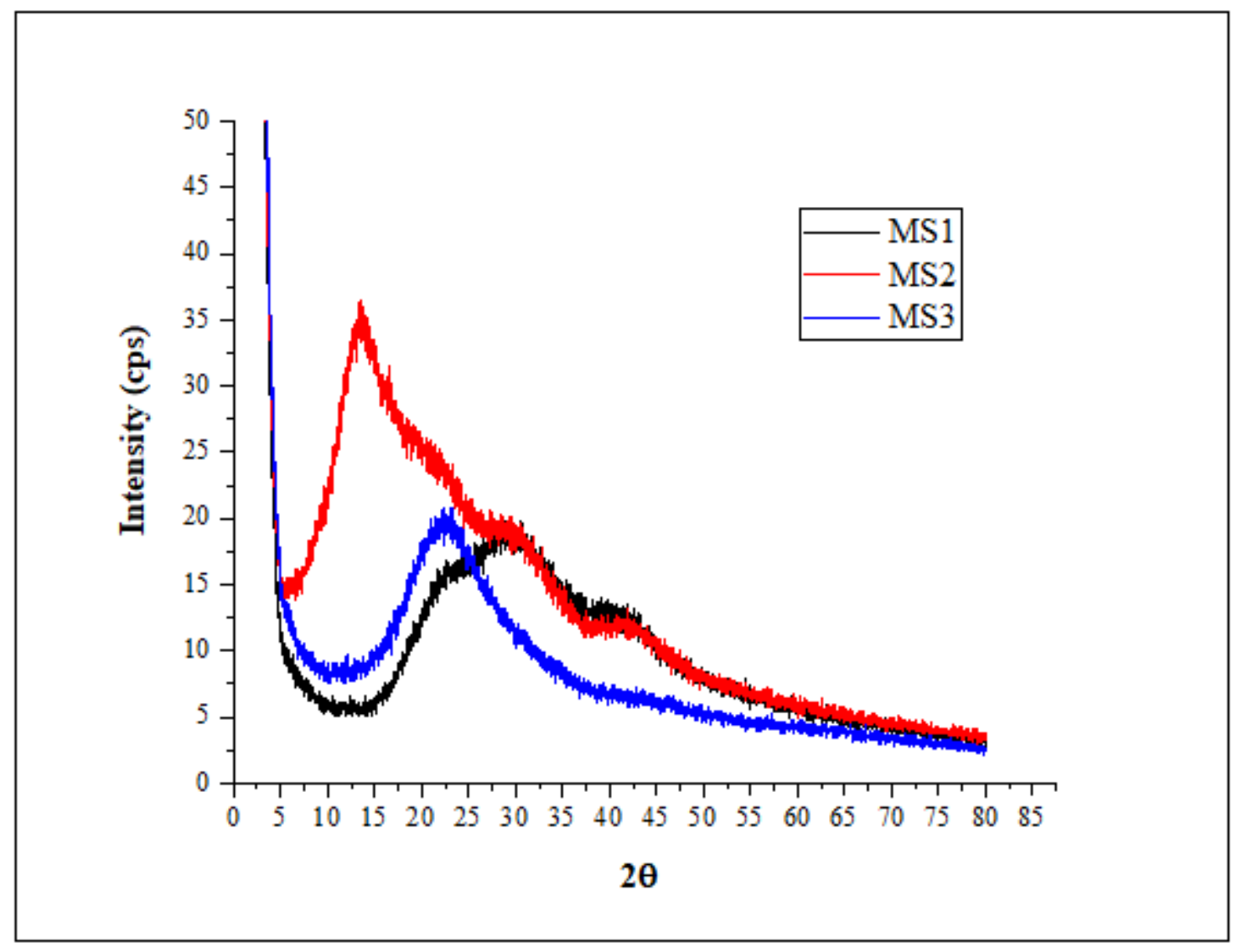

Figure 4

Diffraction pattern of mesoporous silica 

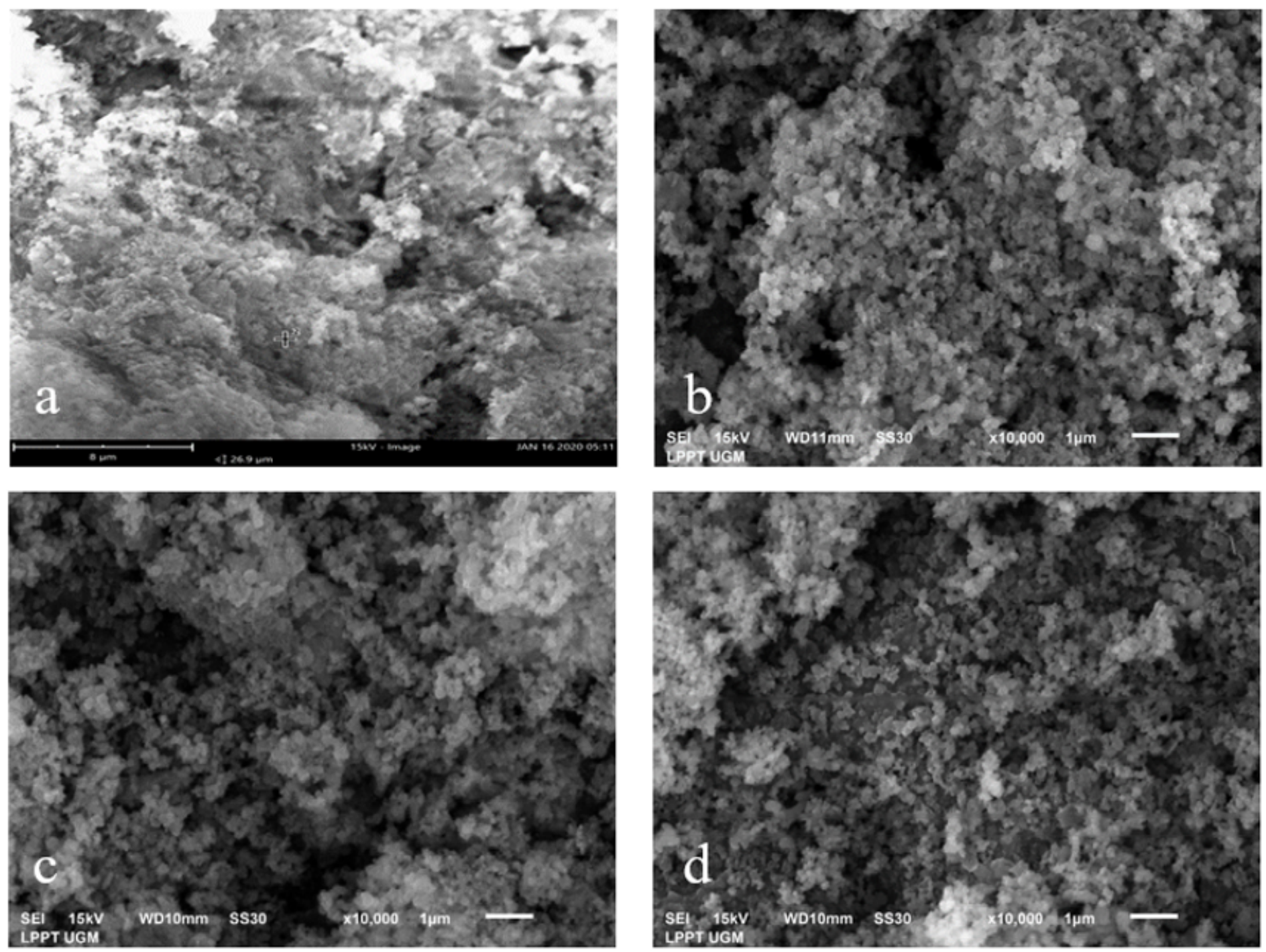

Figure 5

Surface morphology of images of (a) Silica, (b) MS1, (c) MS2 and (d) MS3
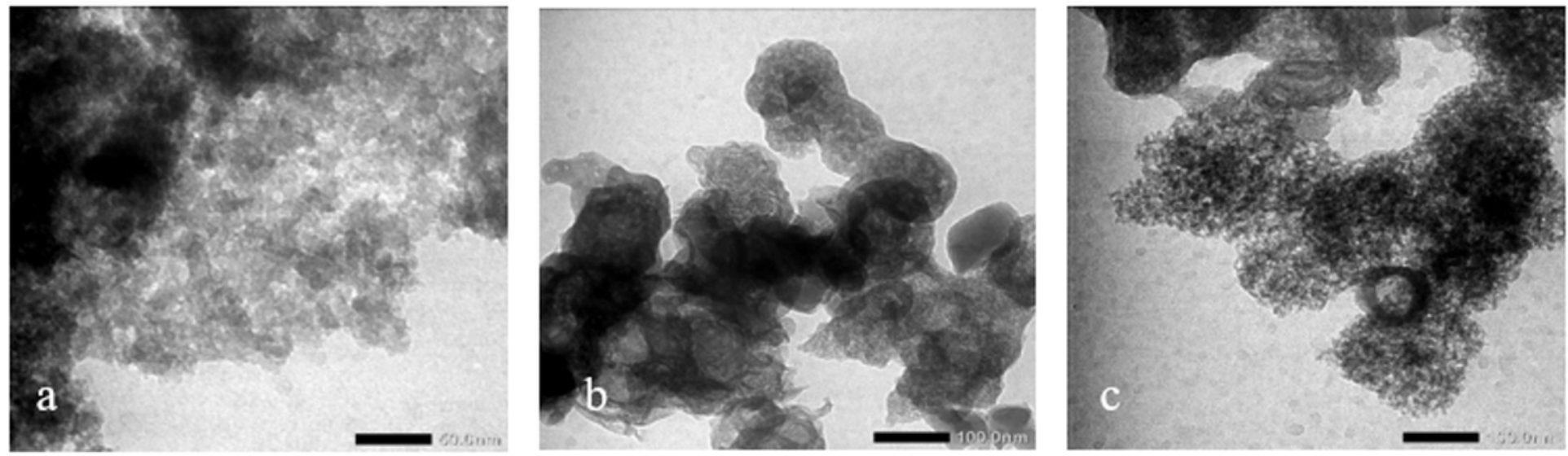

Figure 6

TEM images of the mesoporous catalyst (a) MS1, (b) MS2 and (c) MS3 


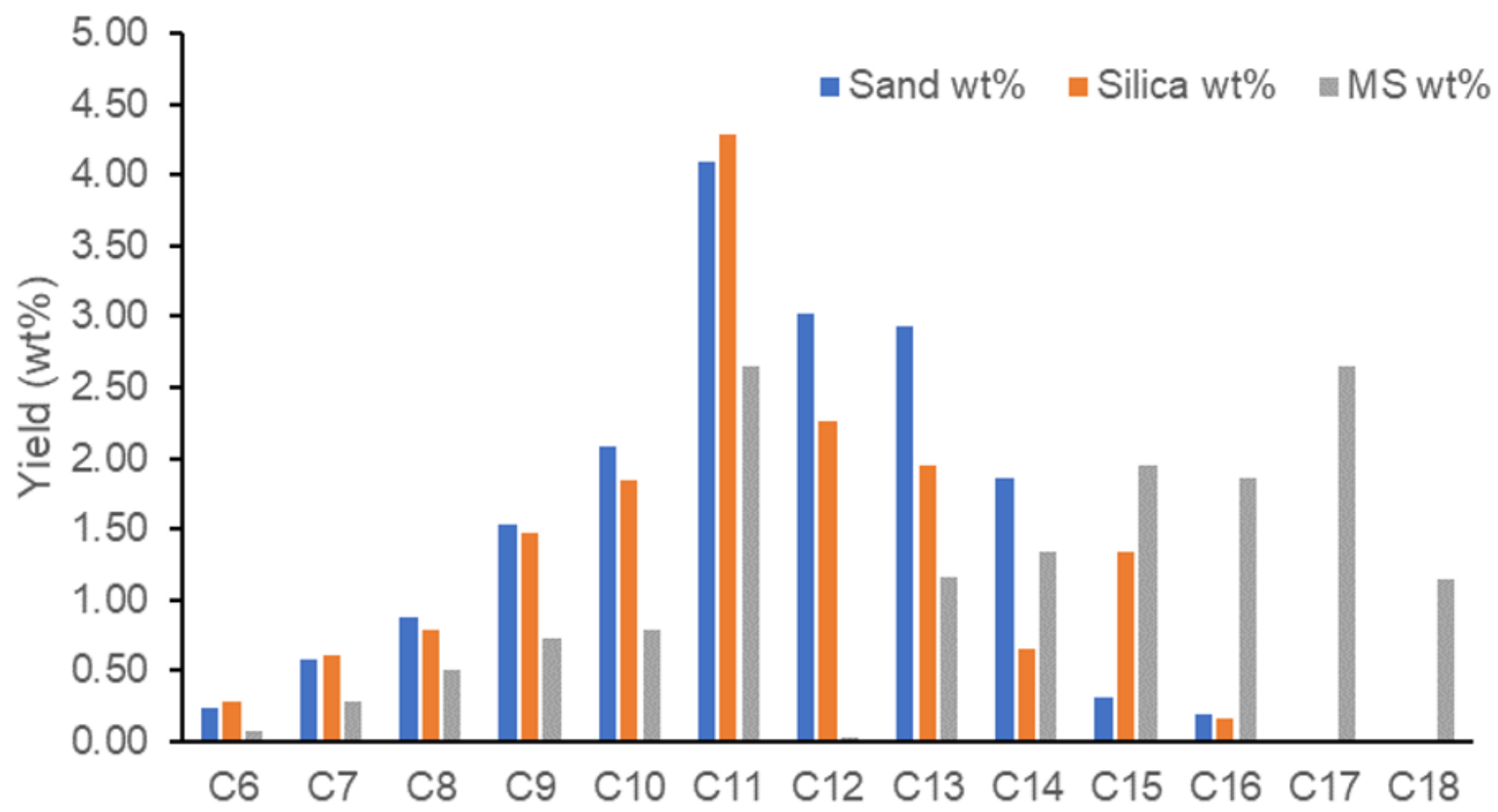

Figure 7

Hydrocarbon distribution from hydrocracking of waste cooking oil.
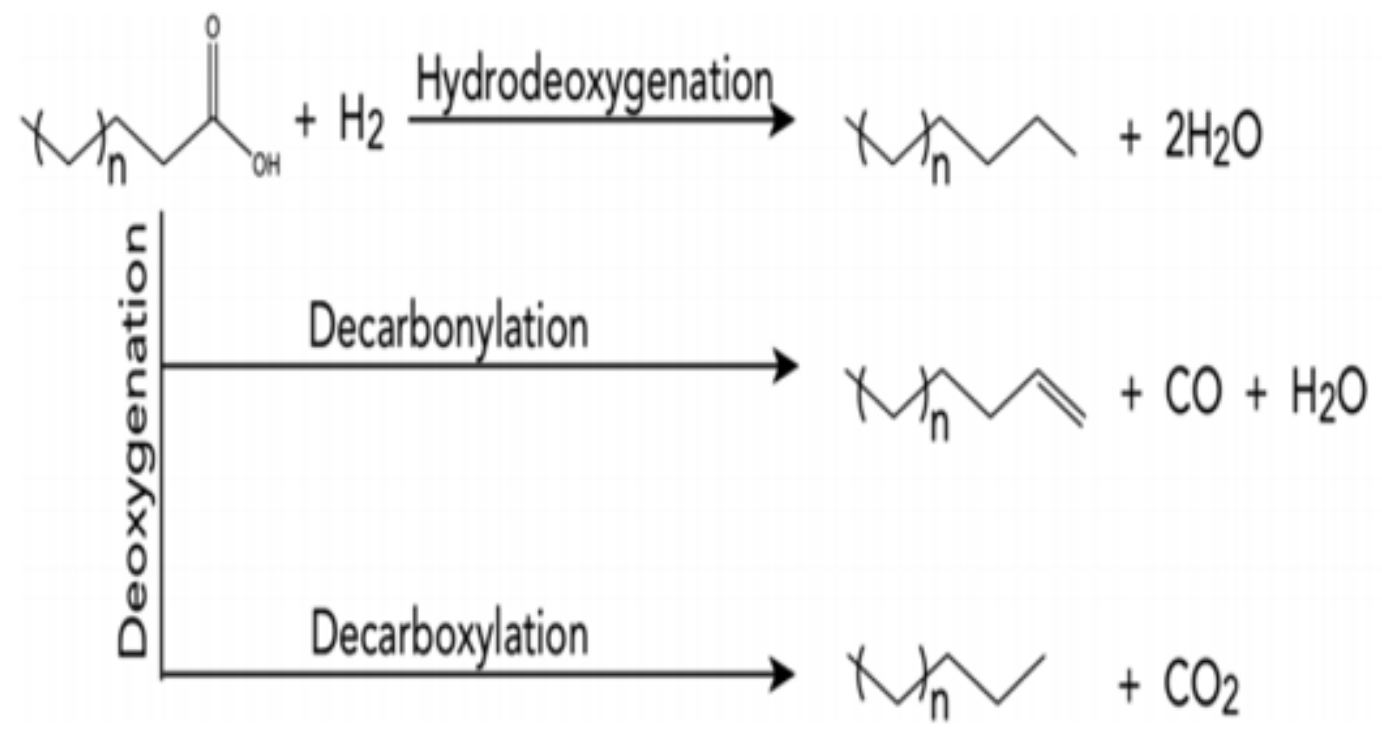

Figure 8

Hydrocracking reaction mechanism of waste cooking oil 